\title{
INSIGHTS PROVIDED INTO THE DECOLONISATION OF THE SCIENCE CURRICULUM, AND TEACHING AND LEARNING OF INDIGENOUS KNOWLEDGE, USING CULTURAL-HISTORICAL ACTIVITY THEORY
}

\section{J. J. de Beer}

Research Unit Self-Directed Learning

North-West University

Potchefstroom, South Africa

https://orcid.org/0000-0002-2411-6599

\author{
J. Kriek \\ Department of Physics \\ University of South Africa \\ Pretoria, South Africa \\ https://orcid.org/0000-0001-6248-4563
}

\section{ABSTRACT}

This article explores the budding scholarship related to the decolonisation of the South African curriculum, by making use of third-generation Cultural-Historical Activity Theory (CHAT) as a lens. In the article the authors advocate for the use of indigenous knowledge as a vehicle for curriculum transformation. The article has a binomial nature, in so far that the first section considers the decolonisation of the higher education curriculum through the infusion of indigenous knowledge, by making use of CHAT. The last section reflects on empirical findings of a teacher professional development (TPD) intervention related to epistemological border-crossing between indigenous knowledge and natural sciences. CHAT is especially valuable in indigenous knowledge (IK) research, due to its emphasis on both cultural and historical contexts. In-service natural sciences teachers were assisted in their professional development to better contextualise the school curriculum for culturally diverse learners, through the infusion of indigenous knowledge. The findings reveal that there are tensions between the intended and realised curriculum, and that teacher professional development does not necessarily lead to the transfer of knowledge and skills in the classroom. Using indigenous knowledge as a vehicle to decolonise the curriculum, holds affordances for the rediscovery and appreciation of people's own history, culture, language and identity.

Keywords: decolonisation of the curriculum, indigenous knowledge, teacher education; CulturalHistorical Activity Theory 


\section{INTRODUCTION: INDIGENOUS KNOWLEDGE AND DECOLONISING THE CURRICULUM}

Curriculum reform is a universal occurrence (Girvan, Conneely, and Tangney 2016), and it is necessary that the reformed curriculum address 21 st century skills, incorporate information and communications technology (ICT), and change the assessment practices in classrooms. However, South Africa does not only face curriculum changes similar to other countries, our higher education has been characterised by protests that relate to issues of not only transformation, but also of the relevance of the curriculum. Le Grange $(2019,26)$ states that for protesting students, "the Rhodes statue was a symbol of institutional racism and exclusion that they experienced at the university". De Beer $(2019,3)$ refers to Mbembe (2015) who wrote, "there is something profoundly wrong when syllabi designed to meet the needs of colonialism and Apartheid continue well into the post-Apartheid era". Le Grange $(2019,29)$ describes decolonisation as having to "represent a broader process whereby colonised peoples correct the deficient ways in which they have come to be defined, seek self-determination, discover and recover their indigenous knowledge and sense of self, and mourn the pain inflicted upon them by colonisation". Authors such as De Beer (2016) sees indigenous knowledge as a powerful vehicle to achieve the decolonisation of the curriculum. Le Grange $(2019,43)$ agrees, and argues that "there are voices that have been silenced in the decolonisation conversations, and I am not referring to human voices, but the voices of the more-than-human world. It is the voice that indigenous peoples know and have come to understand. Indigenous people, for example, know the importance of listening to the voice of the land - that the land is their teacher and not something that is to be possessed". This article argues for the inclusion of indigenous knowledge in the transformed curriculum, and significant work has especially been made in terms of the science curriculum (Cronje, De Beer, and Ankiewicz 2015; De Beer 2016; Mentz and De Beer 2019a), in an attempt to better contextualise the "western" curriculum and make it relevant to diverse South African learners. However, in this article we utilise a specific research lens, namely Cultural-Historical Activity Theory, to shed light on indigenous knowledge as a way of decolonising the curriculum.

This research is not only relevant to the South African context, but also of international importance. Currently, the schooling systems in Europe, Americas and other countries are experiencing change due to the influx of immigrants in schools. This influx of immigrants brings challenges as well as opportunities to the classroom. Challenges such as shifting from homogeneous classrooms where students speak the same language, to classrooms that need to accommodate different languages and making, often abstract, western curricula relevant to diverse learners. Having students from different backgrounds (also cultural backgrounds) in a 
classroom could also introduce opportunities in terms of the wealth of indigenous knowledge these students bring to the classroom.

Balfour (2019, xxxvii) makes the statement that the decolonisation of the curriculum debate in South Africa should commence beyond simply post-colonial literary studies, and also "positioning indigenous knowledge systems as a means through which curriculum and curriculum making, pedagogy and teaching methodologies come to be revisioned". The Cultural-Historical Activity Theory (CHAT) lens is especially valuable in indigenous knowledge research, due to its emphasis on both cultural and historical contexts.

The aim of the article is to use CHAT as a lens to firstly, focus on the decolonisation of curricula in higher education through the inclusion of indigenous knowledge, and secondly, to illustrate with a practical example, of research done in the field of in-service teacher education, how two cycles of Teacher Professional Development (TPD) interventions provide insights into the teaching and learning after the infusion of indigenous knowledge into the science curriculum.

\section{CULTURAL-HISTORICAL ACTIVITY THEORY}

Cultural-Historical Activity Theory (CHAT) has been referred to as "a cross-disciplinary framework for studying how humans purposefully transform natural and social reality, including themselves, as an ongoing culturally and historically situated materially and socially mediated process" (Roth, Radford, and LaCroix 2012, 1). An activity system is a concept devised by Engeström (1987) and refers to how people interact in a bounded system. Such an activity system can be a classroom, a curriculum or teacher professional development (TPD). An activity system comprises of a subject (e.g., the student), an object (the purpose or goal of the activity system, e.g., becoming a self-directed learner) and tools that are utilised to facilitate the achievement of the object (e.g., various pedagogies, teaching and learning materials or semiotic tools). An activity system is guided by certain "rules", e.g., the rules related to graduation at a university or teaching and learning policy documents advocating for specific pedagogies. The "community" includes all stakeholders in the activity, e.g., in a university lecture hall, the students, lecturer, university management, extra-curricular activities stakeholders and future employers. The "division of labour" refers to the different roles of the subject, e.g., the student as a self-directed learner, the student as a reflective learner or the student as an agent of change.

CHAT can be used on three levels, namely (a) on a personal plane, focusing on the individual (e.g., the student or the teacher), (b) on an interpersonal plane, where the dynamic interaction is considered between two individuals (e.g., the student and the teacher), and (c) on 
an institutional plane, where the "subject" is a phenomenon (Mentz and De Beer 2019a, 56). In Figure 1, CHAT is used in the traditional way, namely with the "subject" being the student.

Engeström $(2009,310)$ stated: “In today's interconnected world, it is often useful to take two interdependent activity systems as the minimal unit of analysis." That would mean that two interdependent activity systems are juxtaposed (Mentz and De Beer 2017; 2019a). Figure 1 provides such a third-generation CHAT perspective on two inter-dependent activity systems. In figure 1, the traditional higher education curriculum (left hand figure) is juxtaposed with a transformed (decolonised) curriculum. Third-generation CHAT shows potential levels of tensions, conflict or in activity theory language, "dramatical collisions" (Veresov 2007).

The object of both curricula should be to adequately prepare the student with the knowledge and skills needed in a complex 21 st century. However, the activity systems differ in terms of "rules" that govern the activity (learning), and the "tools" that are used. This could lead to "tensions" in an activity system.

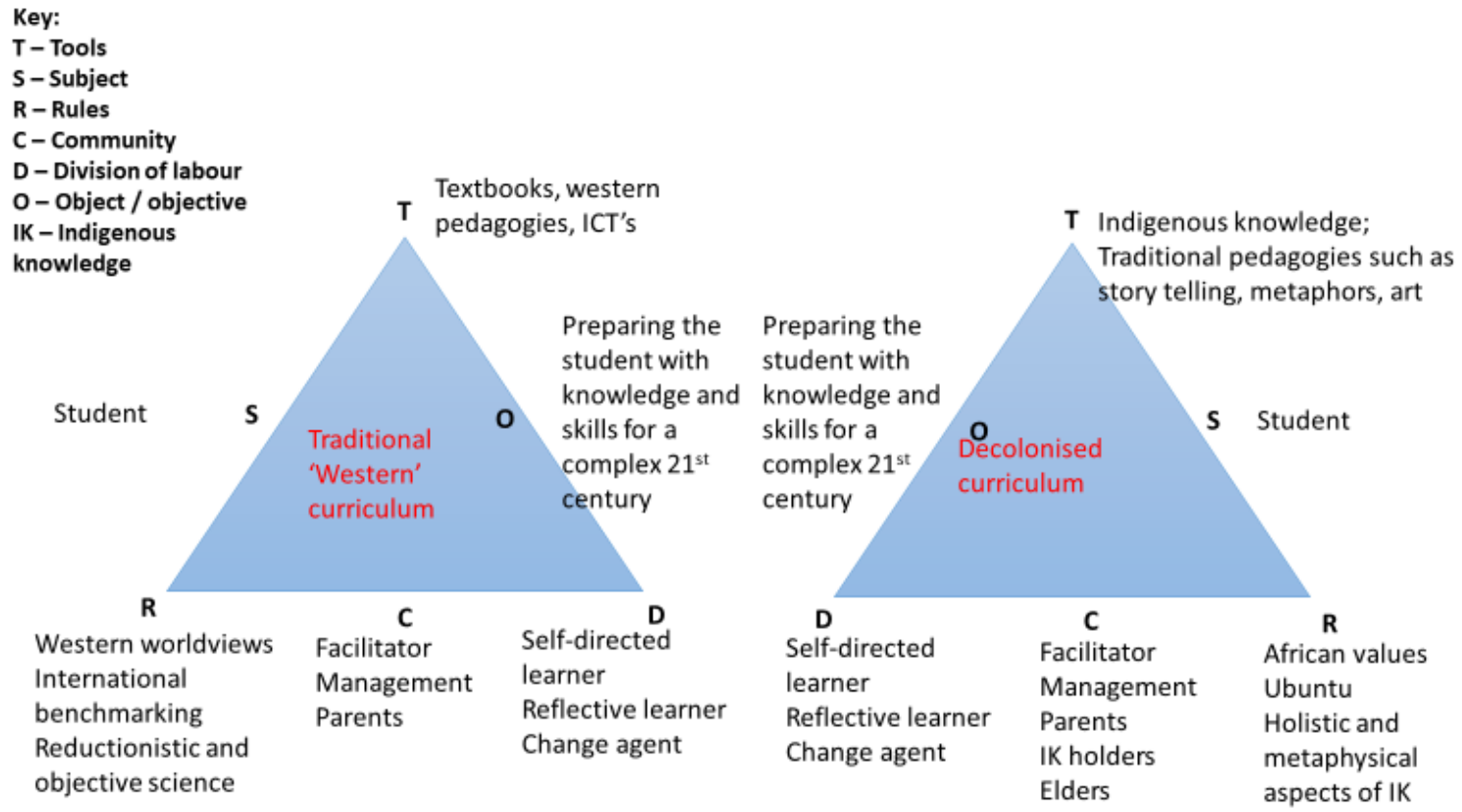

Figure 1: Juxtaposing a transformed curriculum with the traditional (Western) curriculum

Indigenous knowledge holds affordances to better contextualise, and "decolonise", the western curriculum. Scholars advocating for the use of indigenous knowledge as a way to address the decolonisation of the curriculum, often use embodied, situated and distributed cognition (Hardy-Vallee and Payette 2008) as framework. However, this asks that teachers/lecturers/facilitators will have to rethink the "tools" (pedagogies) used. Also, it should be realised that indigenous knowledge is holistic, and that it also includes metaphysical aspects (the "rules" underpinning the curriculum). This is in contrast to the objective and reductionist 
western science curriculum. By way of example, ethnobotany (the study of how cultural groups have traditionally used plants as food or medicine), could be an effective vehicle to better contextualise the botany curriculum for culturally diverse students. Students can engage in activities such as the Kirby-Bauer technique (De Beer 2019) to test the antimicrobial properties of plants that have been traditionally used to combat pathogens. Such an activity will highlight the shared tenets between science and indigenous knowledge, e.g., that both have an empirical base. However, such an activity alone will not provide students with a true understanding of the true nature of indigenous knowledge systems. De Beer (2020) emphasises that most indigenous knowledge systems are characterised by metaphysical aspects ("magic" plant use). One's first reaction is that such "pseudo-science" should be rejected, but its exclusion would mean that an incomplete picture is painted of indigenous knowledge systems. De Beer and Van Wyk (2019) claim that there are often rational explanations for "magic" plant use, upon closer inspection. These authors refer to the use of a traditional plant "impinda" (Adenia gummifera) which is traditionally sprinkled around the house to inhibit "evil spirits", that at first sight, seems highly irrational. This plant has strong antimicrobial properties, and De Beer and Van Wyk (2019, 130) show that "impinda" serves the same purposes as disinfectants and bleaches in modern homes, namely to kill micro-organisms that could cause disease. It thus becomes clear that there might be plausible reasons for such plant use. Such aspects should also be discussed ("tools") in the classroom.

CHAT provides a lens to critically look at the complex epistemological border-crossing between the natural sciences and indigenous knowledge systems, and could assist curriculum developers to consider aspects such as guidelines ("rules") that should govern the inclusion of indigenous knowledge in the curriculum/classroom, as well as the most appropriate "tools" (pedagogies) to facilitate such border-crossing.

\section{METHODOLOGY}

The rest of this article focuses on empirical research on a teacher professional development (TPD) intervention in which natural sciences teachers were assisted to infuse indigenous knowledge into science curriculum content. Design-based research was followed as it allows for continuous improvement of an intervention (Sari and Herrington 2013). Cycle 1 reflects on a TPD intervention (62 teachers) in 2016 in Limpopo Province, and cycle 2 (37 teachers) in the Northern Cape Province during 2017. Convenience sampling was done, as teachers who enrolled for a short learning programme were invited to participate in the research. All these research participants were teachers who taught Natural Sciences in the Senior Phase (grades 79), and/or Life Sciences in FET Phase (grades 10-12). The teachers all met the enrolment 
criteria of the NWU, e.g., they were all qualified teachers. Data was collected through questionnaires, portfolios, classroom observations and interviews.

The views-on-the-nature-of-indigenous-knowledge (VNOIK) questionnaire (Cronje et al. 2015) determines teachers' understandings of the nature of indigenous knowledge, and its alignment to the tenets of science. In terms of the portfolios, the teachers needed to include lesson plans on facilitation of IK in science, problem-based learning (PBL) and cooperative learning. The Reformed Teaching Observation Protocol (RTOP) instrument (Sawada, Piburn, and Judson 2002) was used during classroom observations after the intervention, to determine whether the transfer of new knowledge and skills took place. During the individual interviews, questions were asked to capture experiences of the TPD to establish if the teachers included IK in their teaching, and if they did, how, and if they did not, why not.

Data was analysed using a rubric with categories that indicated an informed view, partially informed view and an uninformed view in the VNOIK questionnaire (Cronje et al. 2015). In the RTOP, a 5-point Likert scale, indicating non-occurrence (0) to very descriptive (4) with various grades in between, was used, while in the interviews, the Saldana (2009) coding technique was used by providing in-vivo codes used (the exact phrasing of teachers in the interviews and portfolios) to identify categories which were then regrouped to form themes.

The results were further analysed by making use of third-generation CHAT (Engeström 1987), as explained above. Categories emerging from the two data sets - cycle 1 and 2 informed the overall themes.

Ethical clearance was obtained (NWU-00271-16-A2) and the teachers participated voluntarily in the study.

\section{DESIGN OF THE TEACHER PROFESSIONAL DEVELOPMENT (TPD) INTERVENTION}

The infusion of indigenous knowledge in the science curriculum requires expertise among teachers and having the competencies to facilitate epistemological border-crossing between indigenous knowledge and "Western" science. Therefore, a nuanced understanding of the tenets of science and indigenous knowledge respectively is critical. Taylor and Cameron (2016), as well as Zinyeka, Onwu, and Braun (2016) distinguish among three perspectives: the view that (a) indigenous knowledge is part of science; (b) indigenous knowledge and science are separate domains of knowledge; and (c) science and indigenous knowledge are seen as intersecting domains. In the interventions reported on in this article, we took the latter approach.

Opportunities need to be provided for in-service teachers to incorporate science and indigenous knowledge in the classroom. This can be done using teacher professional 
development as this involves teacher learning that enables transfer into student learning (Kennedy 2014) that takes place in the classroom. As most teachers were not trained in indigenous knowledge systems, a teacher professional development (TPD) intervention was developed on how to infuse indigenous knowledge into western curriculum themes. However, not all opportunities result in teacher change and very few result in students' achieving the required outcomes (Garet et al. 2001). Therefore, after reflecting on the first TPD, changes were made and a second TPD was implemented.

The initial TPD intervention was developed after careful consideration of a review of literature (Desimone 2009; Desimone et al. 2002; Garet et al. 2001; Supovitz and Turner 2000; Hawley and Valli 2000; Penuel et al. 2007; Clarke and Hollingsworth 2002; Davis and Krajcik 2005; Schneider et al. 2002; Wilson 2013; Kennedy 2014; Earley and Porritt 2014; Whitworth and Chiu 2015; Tooley and Darby 1998; Goldacre 2013; Blair 2016). This resulted in adopting 12 design principles for professional development. In the following section, each of the principles will be presented shortly and explain how it was implemented.

\section{Focus on specific content}

During the TPD intervention, opportunities were provided on how to transfer indigenous knowledge into the mathematics, science and technology classroom. Experts in each of the fields, mathematics, science and technology, assisted in scaffolding teachers' learning through the creation of learning activities embedded in authentic problems. For example, the Kirby Bauer technique was used so that teachers could engage with the scientific method in indigenous knowledge research.

\section{Alignment of curriculum and policies to ensure coherence}

Consideration is given to align learning activities, during the teacher professional development intervention, with specific curriculum content, which will ensure transferability to the classroom. For example, during the TPD, the facilitators showed teachers how indigenous knowledge can be taught by taking the tenets of science into consideration, for specific sections in the Natural and Life Sciences curricula. These shared principles of science and indigenous knowledge ensure that both knowledge systems are empirical, experiential and objective.

\section{Engage in active learning}

In each of the different fields, teachers were physically engaged in activities and not just observing demonstrations. For example, in the technology classroom, it was expected of teachers to build a structure (bridges) using low cost equipment, and engage in the technological design process as emphasised in the school curriculum. 


\section{Activities need to be practised}

TPD should immerse teachers in physically performing activities. The rationale stems from neuroscientific work in embodied, situated and distributed cognition (Hardy-Vallee and Payette 2008). This theory on cognition states that "cognition is physiologically embodied, socioculturally situated, and ostensibly distributed among individuals" (Chahine 2013, 434). Teachers experienced the jigsaw method as part of cooperative learning activities. Hands-on apparatus were provided and teachers had to engage in problem-based activities, and they had to plan lessons integrating indigenous science. They were also engaged in using De Bono's Six Thinking Hats (De Bono 1985), thus providing different perspectives on indigenous knowledge.

\section{The programme must be of sufficient duration (intensity and contact hours)}

After the three-day face to face intervention, teachers were expected to transfer their competencies to the classroom and provide evidence thereof in their portfolios. The teachers had to submit portfolios of classroom activities, by providing lesson plans on how they integrated indigenous knowledge, within five months after the face to face intervention.

\section{Teachers need to be reflective practitioners}

As part of the teachers' portfolios, they had to reflect on their teaching over the five months, and indicate both the successes and challenges encountered in such epistemological bordercrossing in the classroom.

\section{Provision of useful materials}

Before the face to face intervention, learning materials were developed to enhance self-directed learning. Teachers also received teaching and learning resources such as textbooks, posters and laboratory equipment, to enhance inquiry learning in the classroom.

\section{Involvement in inquiry experiences}

Problem- and project-based activities were emphasised, e.g., doing ethnobotanical surveys, using the Matrix Method (De Beer and Van Wyk 2011). Such ethnobotanical projects could teach valuable 21 st century skills to learners, e.g., sampling techniques, conducting interviews and analysing data.

\section{Establish teacher needs before planning TPD}

Before the TPD was developed, pre-questionnaires were sent out to establish the teachers' 
needs, rather than the facilitators deciding on what they thought the teachers' needs were.

\section{Transfer must be researched after TPD}

To establish if transfer of knowledge has been facilitated, there is a need for research. Research included an overview of what worked and what did not work, and how to improve the intervention after every cycle.

\section{Collaboration with the Department of Education}

TPD cannot be done in isolation. There is a need to interact with officials from the Department of Education, as their support is of the utmost importance to ensure transfer to the classroom.

\section{A theoretical framework should underpin TPD}

The intervention was conceptualised from a social-constructivist perspective and drawing on Warford's (2011) concept of the zone of proximal teacher development (ZPTD), an adaptation of Vygotsky's (1978) construct of the zone of proximal development (ZPD).

The initial TPD intervention as the first cycle, was designed using these principles from literature. This cycle was reviewed and adjusted before the implementation of the second cycle. During each cycle the Cultural-Historical Activity Theory (CHAT), as research lens, was used to provide insights into the teaching and learning in these complex contexts.

\section{RESULTS}

\section{VNOIK questionnaire: Comparing cycle 1 and cycle 2}

The pre- and post VNOIK questionnaires were conducted prior to and after the intervention, respectively. Both cycles are captured (see Table 1).

Table 1: Teachers' understanding of the VNOIK

\begin{tabular}{|l|c|c|c|c|}
\hline $\begin{array}{c}\text { View of participants } \\
\mathbf{N = 6 2}\end{array}$ & $\begin{array}{c}\text { Pre- } \\
\text { questionnaire } \\
(\mathbf{\%})\end{array}$ & $\begin{array}{c}\text { Post- } \\
\text { questionnaire } \\
(\mathbf{\%})\end{array}$ & $\begin{array}{c}\mathbf{N}=\mathbf{3 7} \\
\text { questionnaire } \\
\mathbf{( \% )}\end{array}$ & $\begin{array}{c}\text { Pre- } \\
\text { questionnaire } \\
(\%)\end{array}$ \\
\hline Uninformed & 8 & 0 & 3 & 0 \\
\hline Partially informed & 80 & 54 & 76 & 25 \\
\hline Informed & 12 & 46 & 21 & 75 \\
\hline
\end{tabular}

Comparing the two cycles, it is clear that after the TPD, more teachers in cycle 2 had informed views compared to teachers in cycle 1. 


\section{Classroom observations: Transfer of knowledge and skills in cycle 1 and cycle 2}

After both cycles of TPD, five lessons were observed in rural schools. Table 2 provides an overview of the lessons, using the different foci of the RTOP instrument. The Likert scale used in the RTOP instrument is based on $0=$ never occurred; $1=$ seldom occurred; $2=$ occasionally occurred; 3 = often occurred; 4 = occurred all the time. Cycle 1 is indicated first, with cycle 2 indicated in brackets.

Table 2: Analysis of the five lessons observed, using the RTOP instrument (cycle 2 in brackets)

\begin{tabular}{|l|c|c|c|c|c|}
\hline & Lesson & Lesson & Lesson & Lesson & Lesson \\
& $\mathbf{1}$ & $\mathbf{2}$ & $\mathbf{3}$ & $\mathbf{4}$ & $\mathbf{5}$ \\
\hline Students' prior knowledge acknowledged & $1(2)$ & $0(3)$ & $1(2)$ & $1(3)$ & $0(2)$ \\
\hline $\begin{array}{l}\text { Focus of lesson determined by learner ideas or } \\
\text { inputs }\end{array}$ & $1(2)$ & $1(2)$ & $1(2)$ & $2(3)$ & $1(1)$ \\
\hline Lesson promoted conceptual understanding & $1(2)$ & $1(2)$ & $1(2)$ & $1(2)$ & $1(2)$ \\
\hline $\begin{array}{l}\text { Students made predictions, estimations and } \\
\text { hypotheses }\end{array}$ & $0(1)$ & $0(2)$ & $0(2)$ & $1(3)$ & $0(2)$ \\
\hline Teacher's questions triggered divergent thinking & $0(2)$ & $1(2)$ & $0(2)$ & $2(3)$ & $1(2)$ \\
\hline Active participation by students & $1(2)$ & $1(3)$ & $1(2)$ & $3(3)$ & $1(3)$ \\
\hline Indigenous knowledge effectively addressed & $1(3)$ & $0(3)$ & $1(2)$ & $2(3)$ & $1(2)$ \\
\hline
\end{tabular}

Changes in teaching approaches and in the effective transfer of indigenous knowledge were noted during the observed lessons in the second cycle, compared to cycle 1.

\section{Interviews: Transfer of cycle 1 to cycle 2}

During both cycles, teachers indicated that there was not enough time to implement indigenous knowledge in the science curriculum as they needed to finish the curriculum. One of the teachers indicated that:

"There is a constant pressure on us as teachers to produce good results. Nowadays, I teach in order to prepare the learners for the examination. I like the idea of indigenous knowledge, but I do not know if I will have enough time to implement it. The CAPS is so demanding."

\section{Portfolios: Transfer of cycle 1 to cycle 2}

The portfolios submitted after cycle 2 provided more evidence of problem-based and cooperative learning strategies. However, in both cycles, there were limited examples of effective infusion of indigenous knowledge into lesson plans.

\section{A CHAT analysis}

A visual representation of teachers' engagement in the TPD (on the left) and the transfer that takes place in the classroom after the TPD (the classroom thus forms the activity system 
indicated on the right) is provided (see Figure 2). Each of the classrooms observed should actually be an activity system on its own, but based on the data, we have decided to compile a generic classroom activity system that resembles the most common characteristics.

In Figure 2, we see the activities of the teacher (engaging in learning activities) during the TPD as the subject, while the object refers to the main aim of the activity system (namely TPD to incorporate indigenous knowledge in the science curriculum). Tools (or mediating artefacts) refer to the pedagogies used by the teacher educators (during the TPD) or the teachers in their classrooms, as well as resources used. Examples of tools were problem-based and cooperative learning methods. As mentioned earlier, an activity system is governed by certain rules. Rules, in this case, refer to the national school curriculum, the tenets of science and indigenous knowledge, and the guidelines that govern problem-based and cooperative learning. It also includes classroom rules that could either improve or impede the realisation of the object (outcomes of the TPD). The community entails all stakeholders, such as the teachers, course facilitators (teacher educators), learners, principal and school governing body, parents, and the Department of Education. With division of labour the different roles of the teacher is the focus, for example, the teacher as a learning facilitator, critical reflective practitioner and agent of change. Figure 2 is a generic illustration and more detail on the respective two cycles are provided in Figure 3 (cycle 1) and Figure 4 (cycle 2). It is hoped that there would be a shared object in the two activity systems, as can be seen in Figure 2 (object 3 ) - this would mean that the TPD was successful.

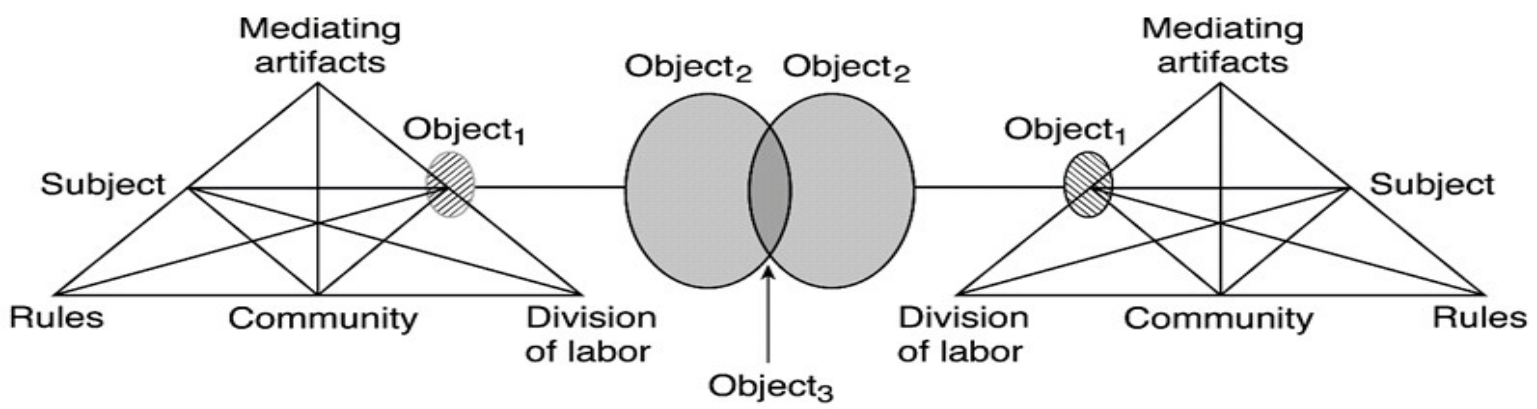

Figure 2: Utilising third-generation CHAT as research lens, juxtaposing two interacting activity systems, with a shared object (Engeström 2001, 136)

\section{Insights provided into the teaching and learning after cycle 1}

Two activity systems are presented in Figure 3. The first activity system provides the teachers' engagement in the TPD (on the left) and is compared with the transfer that takes place in the classroom after the TPD (the classroom thus forms the activity system indicated on the right).

The object is the central construct in the activity system (Engeström 2009). The 
complexity of the object in an activity system often results in what McNeil (2013) refers to as the "contradiction of control", and can be considered as a barometer of tensions (Mentz and De Beer 2017; 2019a).

Object: An example of a "contradiction of control" can be seen between the two triangles, where the objects of the two activity systems are compared (see Figure 3). Teachers generally agreed during the TPD to exchange "chalk-and-talk" approaches for problem-based and cooperative learning strategies. However, the data (especially the lesson plans [RTOP] in the portfolios, and the lesson observations) showed that they reverted to transmission-mode approaches (in the lesson plans) after the intervention (triangle on the right). The data showed that the teachers did not attempt to infuse indigenous knowledge into the curriculum content. This is in contrast to the data obtained through the VNOIK instrument which showed that teachers developed better understandings of the nature of indigenous knowledge. The "contradiction of control" therefore refers to the misalignment of the objects of the juxtaposed activity systems.

Rules: The systemic pressure on teachers to produce good results (refer to the rules in the triangle on the right, in Figure 3) negatively affects the realisation of the desired object (infusing indigenous knowledge into curriculum topics using inquiry learning approaches). The "pace setters" provided by the Department of Education are time frames that are religiously adhered to by teachers. Teachers' adherence to these tight schedules often results in transmission-mode teaching, as many teachers see this as a more effective strategy in preparing learners for the examination (Mentz and De Beer 2017; 2019a; De Beer and Mentz 2016). This finding also emerged from other studies (Ramnarain and Schuster 2014).

Tools: Another "tension" highlighted by CHAT is that the data shows that a lack of resources (refer to tools) also negatively affects the desired object, as many teachers view the absence of a laboratory as a factor in preventing inquiry learning (De Beer 2016; Cronje 2015).

Division of labour: One more tension is between the division of labour and the object. Unfortunately, little evidence of teacher agency was shown. One exception was a teacher who improvised learning activities and resources, when she provided the outline of a project-based assignment, which required the learners to engage in an ethnobotanical survey. During this survey, the learners had to develop an inventory of the major medicinal plants used in their area. The teacher and her learners also interviewed five local, knowledgeable people and developed an elementary ethnobotanical knowledge index (EKI) for the participants, as well as a species popularity index (SPI) (De Beer and Van Wyk 2011). 


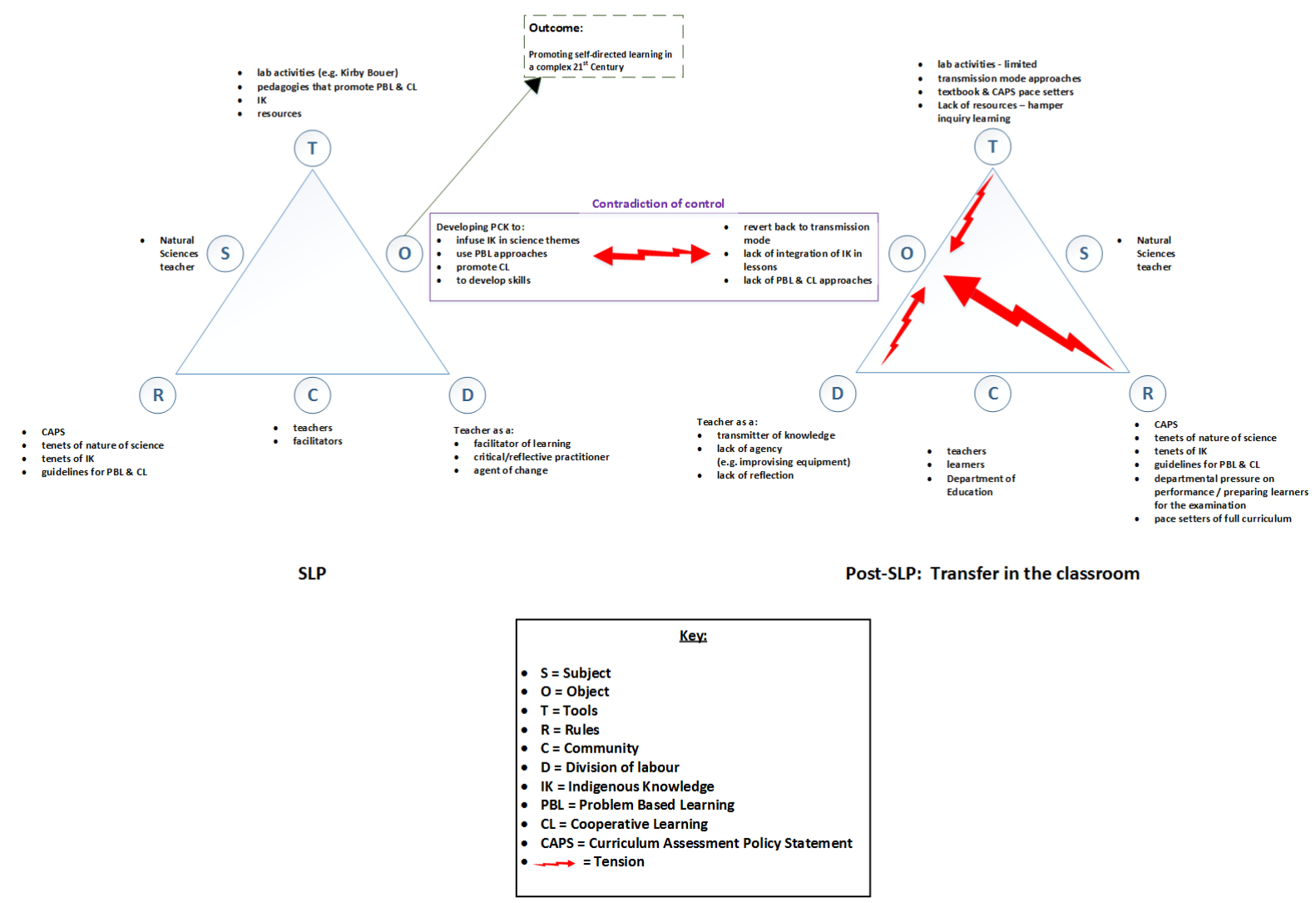

Figure 3: Looking at the TPD of cycle 1 (that took place in Limpopo) through a CHAT lens

\section{Insights provided into the teaching and learning after cycle 2}

When comparing the juxtaposed activity systems in Figure 3 (cycle 1) with Figure 4 (cycle 2), it is clear that there is less of a contradiction of control in the second cycle. There is better alignment between the object of the TPD activity system (on the left) and that of the post-TPD classroom (on the right), in so far as many portfolio lessons provided evidence of engaging learners in problem-based learning and inquiry activities. The portfolios also showed better evidence of the inclusion of indigenous knowledge and provides evidence of more effective transfer of competencies to the classroom after the intervention. There are also fewer tensions in the activity system, as the presence of a "third partner" (funders) resulted in more tools (laboratory equipment) being made available, to engage in meaningful laboratory inquiry work in the classroom. Under "division of labour", there was better evidence of critical teacher reflection and this also contributed to the realisation of the object.

However, this does not mean that "transmission-mode" teaching was entirely shunned in cycle 2 . The same systemic pressures exist for these teachers as for those surveyed in cycle 1 , but the cycle 2 teachers were more willing to exchange transmission approaches for problembased and cooperative learning approaches - despite facing the same challenges in terms of demanding pace setters, or expectations from parents and principals. 
CALVINIA SLP

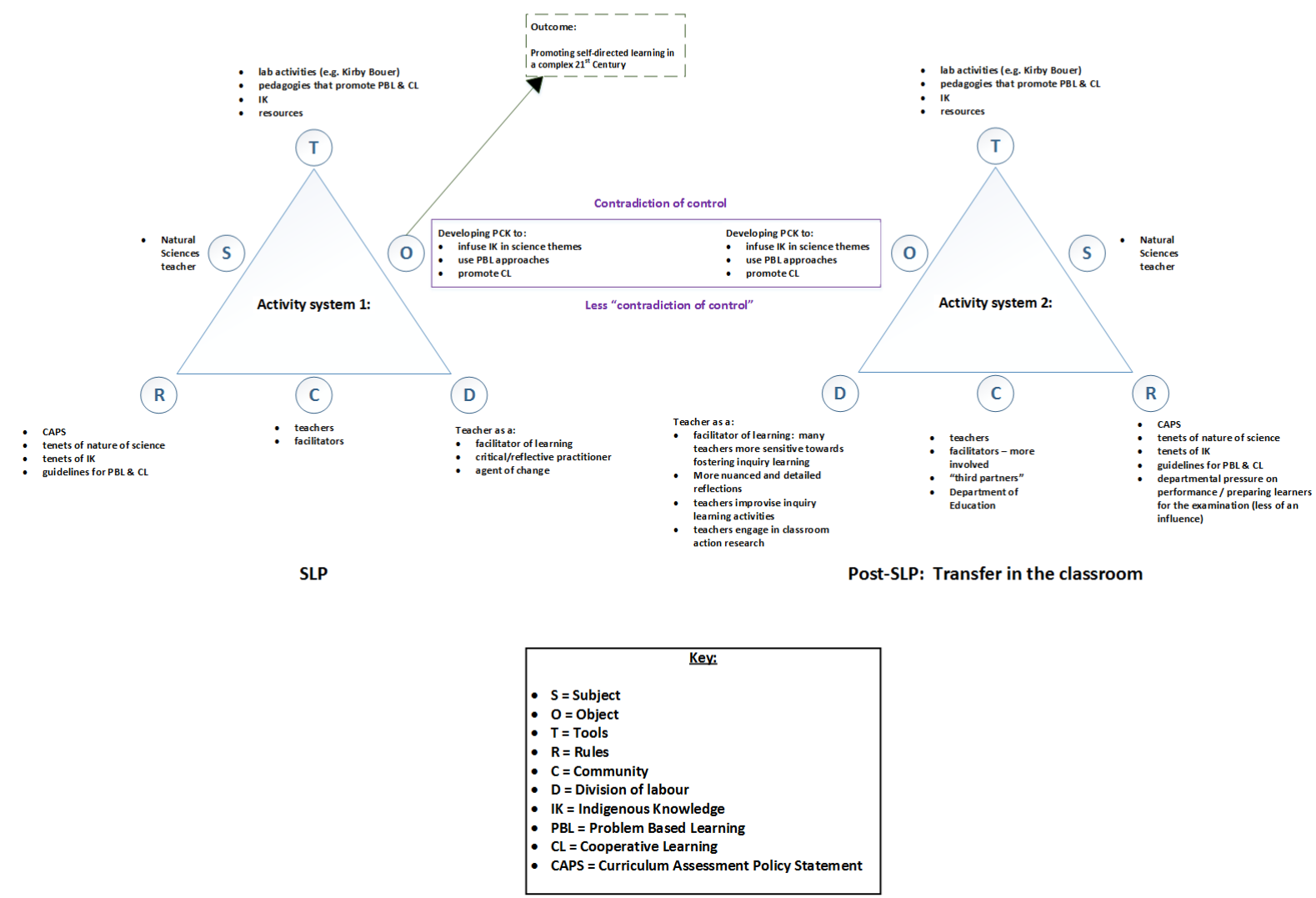

Figure 4: A cultural-historical activity theory perspective on cycle 2, that took place in Calvinia, in the Northern Cape

\section{CONCLUSION}

In this article, we showed the utility value of CHAT as a research lens when indigenous knowledge is considered as a vehicle to "decolonise" the curriculum. CHAT is a metatheoretical framework that could assist curriculum developers, and researchers alike, in interpreting data in complex educational settings. CHAT is especially valuable in indigenous knowledge research, due to its emphasis on both cultural and historical contexts. One should consider that, for decades, indigenous knowledge systems were marginalised in South Africa, due to the political dispensation. De Beer and Whitlock $(2009,210)$ make it clear that, under the Apartheid regime, the Suppression of Witchcraft Act of 1957, which was first introduced in 1895, outlawed all metaphysical aspects of indigenous knowledge, such as divination and premonition (which is at the heart of healing practices in Africa). Also, due to years of neglect and a lack of knowledge, many teachers hold views that indigenous knowledge constitutes pseudo-science, and should be excluded from the curriculum. Using indigenous knowledge as a vehicle to decolonise the curriculum, holds affordances for rediscovery and recovery, a 
process that Le Grange $(2019,29)$ describes as "whereby colonised peoples rediscover and recover their own history, culture, language and identity”. Indigenous knowledge also holds promise to better contextualise curriculum themes to culturally diverse learners, and promote cognition. Researchers such as Chahine (2013) advocate for such border-crossing from an embodied, situated and distributed cognition perspective.

CHAT provides a lens to critically look at the complex epistemological border-crossing between science and indigenous knowledge, and could assist curriculum developers to consider aspects such as guidelines ("rules") that should govern the inclusion of indigenous knowledge in the curriculum/classroom, as well as the most appropriate "tools" (pedagogies) to facilitate such border-crossing. Currently, work is being done on utilising fourth-generation CHAT (Mentz and De Beer 2019b) as a research lens in teacher professional development research. Such an approach emphasises that all stakeholders (the "community" in the activity system) should be included when planning TPD.

\section{ACKNOWLEDGEMENT}

The authors acknowledge the generous funding of the National Research Foundation (NRF) and the Fuchs Foundation, respectively. Views expressed in this article are not necessarily those of the NRF or Fuchs Foundation.

\section{REFERENCES}

Balfour, R. 2019. "Foreword." In The decolonisation of the curriculum project: The affordances of indigenous knowledge for self-directed learning, ed. J. de Beer. Cape Town: AOSIS.

Blair, D. J. 2016. "Experiential learning for teacher professional development at historic sites." Journal of Experiential Education 39(2): 130-144.

Chahine, I. C. 2013. "The impact of using multiple modalities on students' acquisition of fractional knowledge: An international study in embodied mathematics across semiotic cultures." Journal of Mathematical Behavior 32(3): 434-449. https://doi.org/10.1016/j.jmathb.2013.04.004.

Clarke, D. and H. Hollingsworth. 2002. "Elaborating a model of teacher professional growth." Teaching and Teacher Education 18(8): 947-967.

Cronje, A. 2015. "Epistemological border-crossing between western science and indigenous knowledge and its implications for teacher professional development." $\mathrm{PhD}$ thesis. University of Johannesburg.

Cronje, A., J. de Beer, and P. Ankiewicz. 2015. "The development and use of an instrument to investigate science teachers' views on indigenous knowledge." African Journal of Research in Mathematics, Science and Technology Education 19(3): 319-332.

Davis, E. A. and J. S. Krajcik. 2005. "Designing educative curriculum materials to promote teacher learning." Educational Researcher 34(3): 3-14.

De Beer, J. 2016. "Re-imagining science education in South Africa: The affordances of indigenous knowledge for self-directed learning in the school curriculum." Journal for New Generation Sciences 14(3): 34-46.

De Beer, J. 2019. "Glocalisation: The role of indigenous knowledge in the global village." In The decolonisation of the curriculum project: The affordances of indigenous knowledge for self- 
directed learning, ed. J. de Beer. Cape Town: AOSIS.

De Beer, J. 2020. "An ethnobotanical and anthropological study of the medicinal and magic plants of Southern Bushmanland, Northern Cape." Unpublished PhD thesis. University of Johannesburg.

De Beer, J. and E. Mentz. 2016. "Self-directed learning: Lessons from indigenous knowledge holders for school science education." ISTE Conference on Mathematics, Science and Technology Education proceedings, 543-553. 24-28 October, Kruger National Park, South Africa.

De Beer, J. and B-E. van Wyk. 2011. "An ethnobotanical survey of the Agter-Hantam, Northern Cape Province." South African Journal of Botany 77: 741-754.

De Beer, J. and B-E. van Wyk. 2019. "The affordances of indigenous knowledge in decolonising the curriculum, within a self-directed learning framework." In The decolonisation of the curriculum project: The affordances of indigenous knowledge for self-directed learning, ed. J. de Beer. Cape Town: AOSIS.

De Beer, J. and E. Whitlock. 2009. "Indigenous knowledge in the life sciences classroom." The American Biology Teacher 71(4): 209-216.

De Bono, E. 1985. Six thinking hats. New York: Little, Brown and Company.

Desimone, L. M. 2009. "Improving impact studies of teachers' professional development: Toward better conceptualizations and measures." Educational Researcher 38(3): 181-199.

Desimone, L. M., A. C. Porter, M. S. Garet, K. S. Yoon, and B. F. Birman. 2002. "Effects of professional development on teachers' instruction: Results from a three-year longitudinal study." Educational Evaluation and Policy Analysis 24(2): 81-112.

Earley, P. and V. Porritt. 2014. "Evaluating the impact of professional development: The need for a student-focused approach." Professional Development in Education 40(1): 12-129.

Engeström, Y. 1987. Learning by expanding: An activity-theoretical approach to developmental research. Helsinki: Orienta-Konsultit.

Engeström, Y. 2001. "Expansive learning at work: Toward an activity theoretical reconceptualization." Journal of Education and Work 14(1): 133-156.

Engeström, Y. 2009. "The future of activity theory: A rough draft. Learning and expanding with activity theory", 303-328. http://lchc.ucsd.edu/mca/Paper/ISCARkeyEngestrom.pdf.

Garet, M. S., A. C. Porter, L. Desimone, B. F. Birman, and K. S. Yoon. 2001. "What makes professional development effective? Results from a national sample of teachers." American Educational Research Journal 38(4): 915-945.

Girvan, C., C. Conneely, and B. Tangney. 2016. "Extending experiential learning in teacher professional development." Teaching and Teacher Education 58: 129-139.

Goldacre, B. 2013. "Building evidence into education." https://core.ac.uk/reader/9983746.

Hardy-Vallee, B. and N. Payette. 2008. Beyond the brain: Embodied, situated and distributed cognition. Newcastle: Cambridge Scholars Publishing.

Hawley, W. D. and L. Valli. 2000. "Learner-centered professional development." Phi Delta Kappa Center for Evaluation, Development, and Research 27: 7-10.

Kennedy, A. 2014. "Understanding continuing professional development: The need for theory to impact on policy and practice." Professional Development in Education 40(5): 688-697.

Le Grange, L. 2019. Different voices on decolonising of the curriculum. In The decolonisation of the curriculum project: The affordances of indigenous knowledge for self-directed learning, ed. J. de Beer. Cape Town: AOSIS.

Mbembe, A. 2015. "Decolonizing knowledge and the question of the archive." Public lecture, WITS Institute for Social and Economic Research.

McNeil, L. M. 2013. Contradictions of control: School structure and school knowledge. New York: Routledge.

Mentz, E. and J. de Beer. 2017. "The affordances of Cultural-Historical Activity Theory as a research 
lens in studying education from a socio-economic perspective." Paper read at the Fourth Teaching and Education Conference, IISES, Venice, April.

Mentz, E. and J. de Beer. 2019a. "The use of CHAT in researching the affordances of indigenous knowledge for self-directed learning." In The decolonisation of the curriculum project: The affordances of indigenous knowledge for self-directed learning, ed. J. de Beer, 49-86. Cape Town: AOSIS.

Mentz, E. and J. de Beer. 2019b. "The affordances of Change Laboratories for improved sustainability and impact of in-service teacher professional development programmes." Proceedings of the IISES 8th Teaching and Education Conference, 252-271. Vienna, Austria, 17-20 September 2019.

Penuel, W. R., B. J. Fishman, R. Yamaguchi, and L. P. Gallagher. 2007. "What makes professional development effective? Strategies that foster curriculum implementation." American Educational Research Journal 44(4): 921-958.

Ramnarain, U. and D. Schuster. 2014. "The pedagogical orientations of South African physical sciences teachers towards inquiry or direct instructional approaches." Research in Science Education 44: $627-650$.

Roth, W. M., L. Radford, and L. LaCroix. 2012. "Working with cultural-historical activity theory." Forum Qualitative Sozialforschung/Forum: Qualitative Social Research 13(2):1-20.

Saldana, J. 2009. The coding manual for qualitative researchers. London: Sage Publications.

Sari, E. and J. Herrington. 2013. "Using design-based research to investigate the design and development of an online community of practice for teacher professional development." http://researchrepository.murdoch.edu.au/16227/1/using_design_based_research.pdf (Accessed 1 July 2018).

Sawada, D., M. D. Piburn, and E. Judson. 2002. "Measuring reform practices in science and mathematics classrooms: The Reformed Teaching Observation Protocol." School Science and Mathematics 102(3): 245-253.

Schneider, R. M., J. Krajcik, R. W. Marx, and E. Soloway. 2002. "Performance of students in projectbased science classrooms on a national measure of science achievement." Journal of Research in Science Teaching 39(5): 410-422.

Supovitz, J. A. and H. M. Turner. 2000. "The effects of professional development on science teaching practices and classroom culture." Journal of Research in Science Teaching 37(9): 963-980.

Taylor, D. and A. Cameron. 2016. "Valuing IKS in successive South African physical sciences curricula." African Journal of Research in Mathematics, Science and Technology Education 20(1): $35-44$.

Tooley, J. and D. Darby. 1998. Educational research: A critique: A survey of published educational research: Report presented to OFSTED. London: Office for Standards in Education.

Veresov, N. 2007. "Sign mediation: Magic triangle: sign-mediated action and behind." In ISCAR 2007, Fourth Nordic Conference on Cultural and Activity Research, 15-17 June 2007, Norway, Oslo.

Vygotsky, L. S. 1978. Mind in society. Cambridge: Harvard University Press.

Warford, M. K. 2011. "The zone of proximal teacher development." Teaching and Teacher Education 27: $252-258$.

Wilson, S. M. 2013. "Professional development for science teachers." Science 340(6130): 310-313.

Whitworth, B. A. and J. L. Chiu. 2015. "Professional development and teacher change: The missing leadership link." Journal of Science Teacher Education 26(2): 121-137.

Zinyeka, G., G. O. M. Onwu, and M. Braun. 2016. "A truth-based epistemological framework for supporting teachers in integrating indigenous knowledge into science teaching." African Journal of Research in Mathematics, Science and Technology Education 20(3): 256-266. 